\title{
Non-Hodgkin Lymphoma in Psoriatic Arthritis Treated with Sequential, Multiple Anti-TNF- $\alpha$ Agents: A Case Report
}

\author{
Valentina Cestelli*, Gilda Sandri², Eliana Valentina Liardo ${ }^{2}$, Stefano Sacchi and Maria Teresa Mascia ${ }^{2}$ \\ ${ }^{1}$ Rheumatology Unit, Department of Medical and Surgical Sciences for Children and Adults, University of Modena and Reggio Emilia, Italy
} ${ }^{2}$ Department of Diagnostic, Clinical and Public Health Medicine, University of Modena and Reggio Emilia, Italy

\begin{abstract}
Data obtained by large observational studies and meta-analysis indicate the absence of an increased risk of lymphoma related to therapy with anti-TNF- $\alpha$, but there is limited information in literature about the safety of sequential, multiple biological agents therapy for a time longer than three years. We hereby present a case of psoriatic arthritis developing non-Hodgkin lymphoma after a six-year history of poorly effective therapy with different anti-TNF- $\alpha$.
\end{abstract}

Keywords: Anti-TNF- $\alpha$; Psoriatic arthritis; Non-Hodgkin lymphoma

\section{Introduction}

The introduction of drugs designed to inhibit the effects of TNF- $\alpha$ significantly modified the prognosis of multiple chronic inflammatory disorders, including rheumatoid arthritis (RA), psoriatic arthritis (PA), psoriasis and ankylosing spondylitis (AS). In these diseases that require long-term treatment with immunosuppressive therapies, there has always been concern that such treatments could increase the risk of developing cancer.

Biological agents acting through complex mechanisms of immunomodulation and some cytokines inhibited by these treatments (such as TNF- $\alpha$ ) exert important biological effects, although not fully defined, which can counteract the processes of carcinogenesis and tumor progression. We cannot define whether multiple and sequential anti-TNF- $\alpha$ may increase the risk of lymphoma, also due to the difficulty in correctly estimating the risk in patients with RA who already have an increased risk of lymphoma compared to the general population. However, there are some reported lymphoma cases during or after anti-TNF- $\alpha$ treatment in some rheumatic diseases other than RA [1]. Golimumab is a human IgG1 kappa monoclonal antibody approved in 2009 for moderate to severe active RA, active PA and active AS.

\section{Case Presentation}

A 49-year-old woman was admitted to our clinic in 2009 with a history of Crohn disease diagnosed in 2006 following a colonoscopy and a double surgery for rectovaginal fistula, initially treated with sulfasalazine and later with infliximab, then stopped after four infusions following the onset of psoriasis. Next, the patient started therapy with steroids and azathioprine, which were however stopped after a few months due to ineffectiveness. In 2007, the patient suffered onset of asimmetrical hands and feet arthritis, with associated diffuse weakness. Based on the above clinical picture and radiological data, the patient was further diagnosed with PA. A therapy with etanercept plus methotrexate was set, however with no benefit. In February 2009, immunosuppressive therapy was replaced by adalimumab. The clinical manifestations remained steady despite the periodic association of high-dose steroids therapy which was also due to the onset of a subsequent difficulty in walking, aggravated by the presence of a neurogenic pain disease defined as "hereditary neuropathy with predisposition to paralysis compression" (HNPP). In view of the poor control of the arthritis, at the beginning of 2010 the patient was admitted to the Rheumatology Unit and at this stage it was decided to reset therapy with infliximab, also in agreement with the patient; this therapy was stopped after a few months due to adverse events and was replaced by etanercept. In April 2011, the frequent exacerbation of the articular symptomatology, characterized by the onset of arthritis in the ankles and multiple dactylitis, caused the reduction of methotrexate therapy, discontinuation of etanercept and setting the of a therapy with another anti-TNF- $\alpha$ monoclonal antibody, golimumab, which allowed to obtain a gradual improvement in the clinical condition of the patient. In March 2012 the patient complained about the onset of a palpable left inguinal lymph node, which was under investigation for biopsy with histological follicular low-grade non-Hodgkin lymphoma sec. WHO 2008 with a predominantly diffuse and rich in T lymphocytes pattern Mib1-20\%. The blood tests showed minimum levels of leukopenia with normal lymphocytes, ESR at the upper limits, normal LDH and beta2microglobulina and no hypogammaglobulinemia. Following the above histological finding, the patient underwent a hematological evaluation and was subjected to further tests for serological and instrumental staging of lymphoproliferative disease (normal PET and abdominal ultrasound). The inguinal ultrasound showed the presence of bilateral lymphadenopathy with no pathologic feature. Non-Hodgkin follicular lymphomas have a high radio- and chemosensitivity often relapsing after first line treatment. On the basis of the latest evidence reported in literature, a therapy was set with anti-CD20 associated with radiotherapy. Rituximab is a mouse/human chimeric antibody targeting the CD20 antigen on the surface of B-cell lymphoma cells, often used in the treatment of B neoplasms expressing the antigen, and shown to have activity in some autoimmune diseases. In vitro data on B lymphoma cell lines, showed potentiation of radiation-induced apoptosis by addition of rituximab. Data from literature show that combined radio/immunotherapy is feasible and safe and treatment outcome is promising [2,3].

In consideration of the concomitant autoimmune disease, the limited stage (IA) of the hematological disease and comforted by the literature [3], the hematologist proposed a weekly application of rituximab $\left(375 \mathrm{mg} / \mathrm{m}^{2}\right.$ intravenously once a week for 4 weeks)

*Corresponding author: Valentina Cestelli, Rheumatology Unit, Department of Medical and Surgical Sciences for Children and Adults, University of Modena and Reggio Emilia, Via del Pozzo n71, 41124 Modena, Italy, E-mail: v.cestelli@alice.it

Received July 11, 2013; Accepted September 30, 2013; Published October 07, 2013

Citation: Cestelli V, Sandri G, Liardo EV, Sacchi S, Mascia MT (2013) Non-Hodgkin Lymphoma in Psoriatic Arthritis Treated with Sequential, Multiple Anti-TNF-a Agents: A Case Report. Rheumatology 3: 123. doi:10.4172/2161-1149.1000123

Copyright: () 2013 Cestelli V, et al. This is an open-access article distributed under the terms of the Creative Commons Attribution License, which permits unrestricted use, distribution, and reproduction in any medium, provided the original author and source are credited. 
associated with radiation therapy (total dose $30 \mathrm{~Gy}$ ). The therapy was well tolerated: no clinical evidence of residual hematological disease was observed neither during nor after treatment. The patient regularly reported persistent joint pain which was treated with low-dose steroids and analgesic therapy.

\section{Discussion}

Therapy with biotechnological drugs has radically modified the course of chronic inflammatory articular diseases, although it is also associated with an increased risk of serious adverse events, including the onset of malignancies. On the other hand, the same diseases represent, themselves, a risk factor for the development of certain malignancies, so it is not easy to determine whether the same therapy can be considered to be decisive in the development of the latter. Not all the patients satisfactorily respond to the administered treatment, therefore for many years they require continuous therapeutic changes, probably with an increased risk of adverse events. Moreover there are no data in literature which demonstrate whether refractoriness to multiple anti-TNF- $\alpha$ agents increases the risk of malignancies.

Many evaluations of the relative risk of cancer associated with anti-TNF- $\alpha$ have come to differing conclusions, with some but not all meta-analysis of clinical trial data suggesting that these drugs may increase the risk of cancer. An overall increase in the incidence of cancers related to biologics in large observational studies has not been detected, including those carried out on the national Registers (NDB for Rheumatic Diseases for the U.S., Swedish Biologics Register for Sweden, BSRBR for the United Kingdom, BIOBADASER for Spain, LOHREN for Italy and RABBIT for Germany) and the meta-analyses of clinical trials [4-13]. Another recent meta-analysis of data presented in studies of registry and prospective observational studies confirm that the antiTNF- $\alpha$ does not appear to increase the overall risk of developing cancer, with an estimated cumulative risk calculated at 0.95 (95\% CI 0.85-1.05) [14]. Drugs can increase the incidence of malignancies by initiating the cancer process, by promoting progression of a precancerous state to invasive cancer, or both. Limited data are available on time since initiation of therapy and the risk of cancer. An observational study of Askling and coll. conducted on a Swedish database has analyzed the risk of cancer development in time after initiation of anti-TNF- $a$ therapy and the duration of such therapy without encountering an increase of the oncological risk linked to these two variables [5]. Several epidemiological studies show that patients with RA, if compared with the general population, have an increased risk to develop certain type of malignancies, especially lymphoma and cancers of the hematopoietic system, lung and skin cancer other than melanoma [4,6,15-17]. The relationship between RA and lymphoma has been investigated with particular attention. A meta-analysis of studies investigating the risk of overall and four specific malignancies in patients with rheumatoid arthritis compared with the general population showed a doubled risk of lymphoma with a standardized incidence ratio (SIR) of 2.08 (CI 95\% 1.80 - 2.39) [18]. The risk was higher for Hodgkin's lymphoma (SIR 3.29 [95\% CI 2.56 - 4.22]) compared to a non-Hodgkin lymphoma (SIR 1.95 [95\% CI $1.70-2.24]$ ).

It is difficult to define whether anti-TNF- $\alpha$ may increase the risk of lymphoma in RA due to the fact that patients with RA already have an increased risk of lymphoma compared to the general population. A single case reported in the literature shows the development of CD30+ T-cell lymphoma in psoriatic patient treated with ciclosporin and antiTNF- $\alpha$ (infliximab) [19]. However, the main observational studies have not shown an increased incidence of malignant lymphoma probably because the main risk factor for lymphoma seems to lie in the severity of the disease, as demonstrated in a case-control study conducted on the Swedish Inpatient Register during 1964-1995. Such study showed a direct correlation between disease activity and the risk of lymphoma, with an increase of the latter in the subgroup of patients with the highest activity of disease [20]. Therefore, chronic inflammation plays a key role in the risk of lymphoma [20-24]. In order to explain this effect it was assumed that in RA persistent immune stimulation can lead to a clonal selection of B lymphocytes inducing malignant transformation of $\mathrm{CD} 5+$ cells, reducing the number and functional activity of $\mathrm{T}$ suppressor lymphocytes (like those directed against the oncogenic virus, Epstein-Barr) and reducing natural killer cell activity in the synovial fluid, tissue, blood and lymph $[18,20,21]$. Another study of the Swedish group investigated the possibility of a common genetic susceptibility for the development of lymphoma and RA, evaluating whether the increased risk of lymphoma was detectable even before diagnosis of RA [25]. It was observed that the risk increased only in the ten years following the diagnosis of RA, confirming the importance of the disease as a determining factor for the increased risk of lymphoma [26].

Data from the available literature show that the rate of serious adverse events in patients treated with golimumab is comparable to treatment with other anti-TNF- $\alpha$. Specifically, in a multicenter, randomized, double-blind, placebo-controlled trial, 405 patients with active PA were randomly assigned to receive blinded subcutaneous injections of placebo, golimumab $50 \mathrm{mg}$ or golimumab $100 \mathrm{mg}$ at weeks $0,4,8,12,16$, and 20 . Findings over a period of 1 year are reported. The frequency/types of adverse events were similar to those reported at week 24. In particular, two cases of basal cell carcinoma (in patients who received golimumab $50 \mathrm{mg}$ only) were reported. At week 52 , one patient who received golimumab $50 \mathrm{mg}$, died from small cell lung cancer. In addition to this case and the two patients with basal cell skin carcinomas, two additional patients had malignancies. One patient (receiving golimumab $100 \mathrm{mg}$ ) had prostate cancer, and the other (receiving placebo and then golimumab $50 \mathrm{mg}$ after entering the early escape phase) had colon cancer. In this trial no case of lymphoma was reported [27].

\section{Conclusion}

Patients starting anti-TNF- $\alpha$ therapy should be informed that there is no conclusive evidence for an increase in the risk of developing solid tumours or lymphomas above that which would be expected for an RA population, however ongoing vigilance is required. Patients should be examined for potential malignancy if clinically suspected and antiTNF- $\alpha$ treatment should be stopped if malignancy is confirmed. There are no significant differences identified between anti-TNF- $\alpha$ therapies on the risk of malignancy. Clinical trials evaluated the safety of single treatments with biotechnological drugs for a limited period of time. We do not know if the continuous changes in therapy with anti-TNF- $a$ in non responder patients can to constitute a comparable safety profile with respect to patients treated with a single anti-TNF- $\alpha$. Moreover, there are no clinical trials reported in literature which assess such aspect in patients with a history of many years of therapy with one or multiple anti-TNF- $\alpha$. Important information on this topic can be obtained from the evaluation of the national registers. In our case report we decided to treat the patient disease with anti-TNF- $\alpha$ agents comforting about the data of the literature and also because the evidences show that a high disease activity may expose the patient to a higher risk of complications. However the tight control at each stage of the treatment is required. 


\section{References}

1. Ganguly S (2009) Leukemic phase of follicular lymphoma after treatment with etanercept in a patient with psoriasis. Am J Clin Dermatol 10: 125-126

2. Haidenberger A, Fromm-Haidenberger S, de Vries A, Popper BA, Steurer M et al. (2011) Feasibility and toxicity of concomitant radio/immunotherapy with MabThera (Rituximab ${ }^{\circledR}$ ) for patients with non-Hodkin's Lymphoma: results of a prospective phase I/II study. Strahlenther Onkol 187: 300-305.

3. Ruella M, Filippi A, Di Russo A (2012) Addition of rituximab to involvedfield radiotherapy prolongs progression free survival in stage I-II follicular lymphomas: a multicentric, retrospective survey. Haematologica 97: 079.

4. Wolfe F, Michaud K (2007) Biologic treatment of rheumatoid arthritis and the risk of malignancy: analyses from a large US observational study. Arthritis Rheum 56: 2886-2895.

5. Askling J, van Vollenhoven RF, Granath F, Raaschou P, Fored CM, et al. (2009) Cancer risk in patients with rheumatoid arthritis treated with anti-tumor necrosis factor alpha therapies: does the risk change with the time since start of treatment? Arthritis Rheum 60: 3180-3189.

6. Abásolo L, Júdez E, Descalzo MA, González-Alvaro I, Jover JA, et al. (2008) Cancer in rheumatoid arthritis: occurrence, mortality, and associated factors in a South European population. Semin Arthritis Rheum 37: 388-397.

7. Dixon WG, Watson KD, Lunt M, Mercer LK, Hyrich KL, et al. (2010) Influence of anti-tumor necrosis factor therapy on cancer incidence in patients with rheumatoid arthritis who have had a prior malignancy: results from the British Society for Rheumatology Biologics Register. Arthritis Care Res (Hoboken) 62 : 755-763.

8. Carmona L, Abasolo L, Descalzo MA, Pérez-Zafrilla B, Sellas A, et al. (2011) Cancer in patients with rheumatic diseases exposed to TNF antagonists. Semin Arthritis Rheum 41: 71-80.

9. Pallavicini FB, Caporali R, Sarzi-Puttini P, Atzeni F, Bazzani C, et al. (2010) Tumour necrosis factor antagonist therapy and cancer development: analysis of the LORHEN registry. Autoimmun Rev 9: 175-180.

10. Strangfeld A, Hierse F, Rau R, Burmester GR, Krummel-Lorenz B, et al. (2010) Risk of incident or recurrent malignancies among patients with rheumatoid arthritis exposed to biologic therapy in the German biologics register RABBIT. Arthritis Res Ther 12: R5.

11. Geborek P, Bladström A, Turesson C, Gulfe A, Petersson IF, et al. (2005) Tumour necrosis factor blockers do not increase overall tumour risk in patients with rheumatoid arthritis, but may be associated with an increased risk of lymphomas. Ann Rheum Dis 64: 699-703.

12. Setoguchi S, Solomon DH, Weinblatt ME, Katz JN, Avorn J, et al. (2006) Tumo necrosis factor alpha antagonist use and cancer in patients with rheumatoid arthritis. Arthritis Rheum 54: 2757-2764.

13. Burmester GR, Mease P, Dijkmans BA, Gordon K, Lovell D, et al. (2009)
Adalimumab safety and mortality rates from global clinical trials of six immunemediated inflammatory diseases. Ann Rheum Dis 68: 1863-1869.

14. Mariette $\mathrm{X}$, Matucci-Cerinic M, Pavelka $\mathrm{K}$, Taylor $\mathrm{P}$, van Vollenhoven $\mathrm{R}$, et al. (2011) Malignancies associated with tumour necrosis factor inhibitors in registries and prospective observational studies: a systematic review and meta-analysis. Ann Rheum Dis 70: 1895-1904.

15. Askling J, Fored CM, Baecklund E, Brandt L, Backlin C, et al. (2005) Haematopoietic malignancies in rheumatoid arthritis: lymphoma risk and characteristics after exposure to tumour necrosis factor antagonists. Ann Rheum Dis 64: 1414-1420.

16. Askling J, Fored CM, Brandt L, Baecklund E, Bertilsson L, et al. (2005) Risks of solid cancers in patients with rheumatoid arthritis and after treatment with tumour necrosis factor antagonists. Ann Rheum Dis 64: 1421-1426.

17. Thomas E, Brewster DH, Black RJ, Macfarlane GJ (2000) Risk of malignancy among patients with rheumatic conditions. Int J Cancer 88: 497-502.

18. Smitten AL, Simon TA, Hochberg MC, Suissa S (2008) A meta-analysis of the incidence of malignancy in adult patients with rheumatoid arthritis. Arthritis Res Ther 10: R45.

19. Mahé E, Descamps V, Grossin M, Fraitag S, Crickx B (2003) CD30+ T-cell lymphoma in a patient with psoriasis treated with ciclosporin and infliximab. $\mathrm{Br}$ J Dermatol 149: 170-173.

20. Baecklund E, Iliadou A, Askling J, Ekbom A, Backlin C, et al. (2006) Association of chronic inflammation, not its treatment, with increased lymphoma risk in rheumatoid arthritis. Arthritis Rheum 54: 692-701.

21. Smedby KE, Baecklund E, Askling J (2006) Malignant lymphomas in autoimmunity and inflammation: a review of risks, risk factors, and lymphoma characteristics. Cancer Epidemiol Biomarkers Prev 15: 2069-2077.

22. Hansen A, Lipsky PE, Dörner T (2007) B-cell lymphoproliferation in chronic inflammatory rheumatic diseases. Nat Clin Pract Rheumatol 3: 561-569.

23. Martin DN, Mikhail IS, Landgren O (2009) Autoimmunity and hematologic malignancies: associations and mechanisms. Leuk Lymphoma 50: 541-550.

24. Smedby KE, Askling J, Mariette X, Baecklund E (2008) Autoimmune and inflammatory disorders and risk of malignant lymphomas--an update. J Intern Med 264: 514-527

25. Hellgren K, Smedby KE, Feltelius N, Baecklund E, Askling J (2010) Do rheumatoid arthritis and lymphoma share risk factors?: a comparison of lymphoma and cancer risks before and after diagnosis of rheumatoid arthritis. Arthritis Rheum 62: 1252-1258.

26. Sandri G, Cestelli V, Mascia MT (2013) Biological therapy and risk of malignancies: a literature review. Journal of Cancer Therapy 4: 460-465.

27. Kavanaugh A van der Heijde D, Mclnnes IB, Mease P, Krueger GG, et al. (2012) Golimumab in psoriatic arthritis: one-year clinical efficacy, radiographic, and safety results from a phase III, randomized, placebo-controlled trial. Arthritis Rheum 64: 2504-2517.
Citation: Cestelli V, Sandri G, Liardo EV, Sacchi S, Mascia MT (2013) NonHodgkin Lymphoma in Psoriatic Arthritis Treated with Sequential, Multiple Anti-TNF-a Agents: A Case Report. Rheumatology 3: 123. doi:10.4172/2161 1149.1000123
Submit your next manuscript and get advantages of OMICS Group submissions

Unique features:

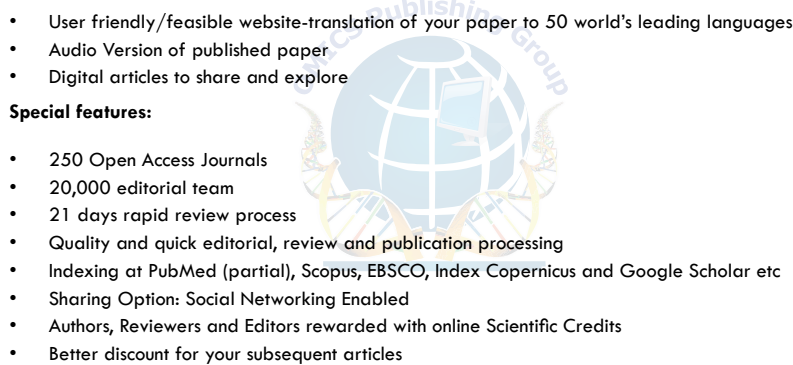

